\title{
Photodegradation of diphenylarsinic acid by UV-C light: Implication for its remediation
}

\author{
Anan Wang ${ }^{\mathrm{a}}$, Ying Teng ${ }^{\mathrm{a}}$, Xuefeng $\mathrm{Hu}^{\mathrm{b}}$, Longhua $\mathrm{Wu}^{\mathrm{a}}$, Yujuan Huang ${ }^{\mathrm{a}}$, \\ Yongming Luo ${ }^{\mathrm{a}, \mathrm{b}, *}$, Peter Christie ${ }^{\mathrm{a}}$ \\ a Key Laboratory of Soil Environment and Pollution Remediation, Institute of Soil Science, Chinese Academy of Sciences, Nanjing 210008 , China \\ ${ }^{\mathrm{b}}$ Key Laboratory of Coastal Zone Environmental Processes and Ecological Remediation, Yantai Institute of Coastal Zone Research, Chinese Academy of \\ Sciences, Yantai 264003, China
}

\section{H I G H L I G H T S}

- DPAA can be degraded into inorganic arsenics under the irradiation of UV-C light.

- The photodegradation of DPAA mainly depended on its direct photolysis.

- The ${ }^{1} \mathrm{O}_{2}$ was generated, but had little effect on DPAA photolysis.

- $\mathrm{Cl}^{-}$promoted the photolytic rate of DPAA, but $\mathrm{NO}_{3}{ }^{-}, \mathrm{NO}_{2}{ }^{-}$and HA inhibited it.

\section{G R A P H I C A L A B S T R A C T}

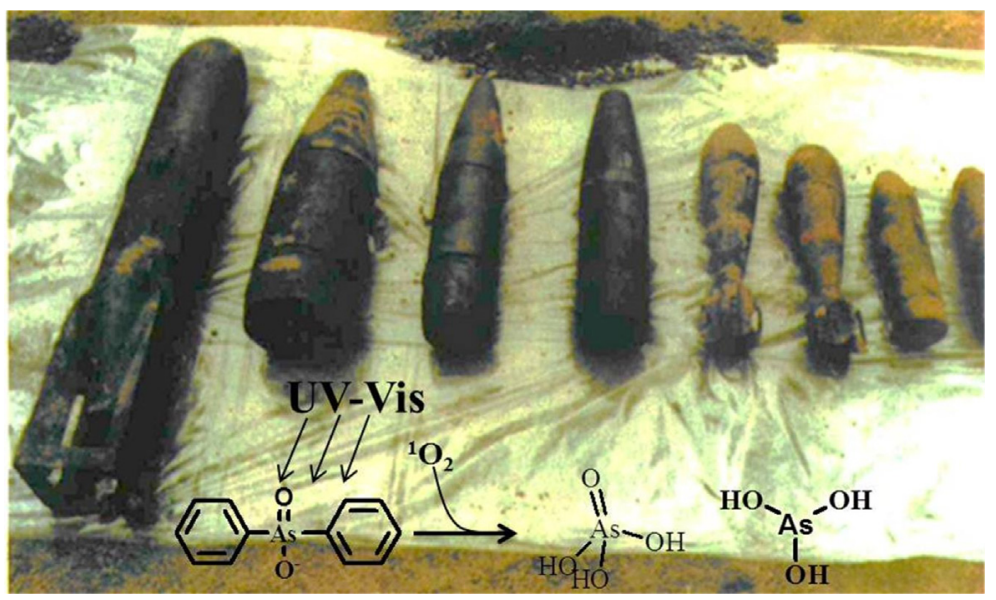

\begin{abstract}
A B S T R A C T
Diphenylarsinic acid (DPAA) is a major contaminant in environments polluted by chemical weapons and abandoned after World Wars I and II and poses high risks to biota but remediation methods for this contaminant are rare. Here, the photodegradtion of DPAA was studied under high-pressure Hg lamp irradiation. DPAA was degraded completely into inorganic arsenic species in 30 min under UV-C irradiation. The photodegradation of DPAA depended mainly on its direct photolysis through excited-state DPAA. By contrast, the generation of ${ }^{1} \mathrm{O}_{2}$ during the photodegradation of DPAA was confirmed by electron paramagnetic resonance (EPR) studies, but ${ }^{1} \mathrm{O}_{2}$ had little effect on the photodegradation of DPAA. Phtotodegradation of DPAA was also studied in soil leachates and groundwater and the photolytic rate of DPAA was controlled by the total organic carbon (TOC) content in soil leachates and by the $\mathrm{NO}_{3}{ }^{-}$concentration in groundwater. Finally, studies on the effects of common solutes on the photodegradation of DPAA show that $\mathrm{Cl}^{-}$can increase the photolytic rate of DPAA by prolonging the lifetime of excitedstate DPAA. Moreover, $\mathrm{NO}_{3}{ }^{-}, \mathrm{NO}_{2}{ }^{-}$, and humic acid (HA) can decrease the photolytic rate of DPAA by suppressing the production of excited-state DPAA. This research shows the detailed mechanism of DPAA photodegradation and provides a new and effective method for DPAA decontamination.
\end{abstract}

(C) 2016 Elsevier B.V. All rights reserved.

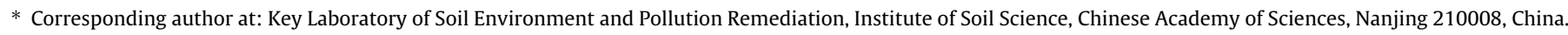
E-mail address: ymluo@yic.ac.cn (Y. Luo).
} 


\section{Introduction}

Phenylarsenicals are widely known as the arsenic-based chemical weapons Clark I (diphenylchloroarsine), Clark II (diphenylcyanoarsine), Adamsite (phenarsazine chloride), and Pfiffikus (phenylarsine dichloride) [1,2]. They were produced extensively during the First and Second World Wars and were discarded in several parts of post-war China, Japan and Europe [3-5]. These agents can be transformed by oxidation and hydrolysis, leading to the formation of diphenylarsinic acid (DPAA) [6]. Numerous studies have detected DPAA as the predominant arsenic species in fields contaminated by residues of chemical warfare agents [7,8]. In Kamisu City, Ibaraki, Japan, DPAA-contaminated groundwater caused central nervous disorders in numerous inhabitants [9]. Thus, the study of environmental transformation processes of DPAA and related phenylarsenicals is important as well as finding effective remediation methods. The latter remains a challenge, mainly because of the slow natural attenuation of DPAA [4].

Some studies have been conducted on the environmental transformation of phenylarsenicals. For example, Arao et al. [10] reported that methylation and dephenylation are key metabolic pathways for DPAA and phenylarsenic acid (PAA) under anaerobic conditions. Several bacterial strains able to degrade DPAA directly have been isolated $[6,11,12]$. In addition, the transformation of PAA and DPAA can be enhanced by indigenous microorganisms under sulfate-reducing conditions $[4,13]$. However, these bioremediation methods cannot degrade DPAA but only transform it into other organic forms and they are time-consuming. More effective decontamination methods are required.

Photodegradation by UV irradiation is a major transformation pathway for chemical compounds and has been used successfully to remediate organic pollutants including organoarsenicals [14-16]. Bednar et al. [17] once reported the photodegradation of roxarsone in soil leachates. Jaworek et al. [18] and Adak et al. [19] applied the UV-based advanced oxidation process (AOP) in the photodecomposition of PAA, roxarsone and nitarsone. The kinetics and mechanism of photo-oxidation of $p$-arsanilic acid by UV irradiation was also investigated $[20,21]$. However, until now there have been no published studies on the photodegradation of DPAA.

In addition, photodegradation can be affected by some common solutes such as humic acids ( $\mathrm{HA}), \mathrm{Cl}^{-}, \mathrm{NO}_{3}{ }^{-}, \mathrm{I}^{-}, \mathrm{CO}_{3}{ }^{2-}$, and $\mathrm{Fe}^{3+}$. $\mathrm{HA}$ and $\mathrm{Cl}^{-}$possess the dual properties of promoting and inhibiting the photodegradation of organic compounds [22,23]. $\mathrm{NO}_{3}{ }^{-}$can retard direct photolysis of organic materials while initiating indirect photolysis through the generation of reactive oxygen species (ROS) [24].

The main aim of the present study was to investigate the photodegradation process of DPAA, the mechanisms involved and the effects of common constituents in natural waters (e.g., $\mathrm{HA}, \mathrm{Cl}^{-}$, $\mathrm{NO}_{3}{ }^{-}$and $\mathrm{NO}_{2}{ }^{-}$). In addition, a proposed degradation pathway was established through identification of the transformation products. The results of this study suggest an efficient method for the removal of DPAA and related phenylarsenicals from contaminated environments.

\section{Experimental section}

\subsection{Chemicals}

DPAA (purity 97\%) was purchased from Wako Company, Osaka, Japan. PAA (purity 99\%) was provided by Aladdin Company, Shanghai, China. Humic acids (HA, Fluka no. 53680) and superoxide dismutase (SOD, 99\%) were purchased from Sigma Aldrich, Inc., Milwaukee, WI. The elemental composition of the HA has been reported to contain: $48.36 \%$ of C, $26.91 \%$ of $\mathrm{O}, 4.24 \%$ of $\mathrm{H}, 0.78 \%$ of
$\mathrm{N}$, and $0.78 \%$ of $\mathrm{S}$, and its atomic ratios $(1.04(\mathrm{H} / \mathrm{C}), 0.42(\mathrm{O} / \mathrm{C})$, and $0.012(\mathrm{~N} / \mathrm{C})$ ) reported in the literature are within the values for soil HAs, except for the N/C ratio [25]. High-performance liquid chromatography (HPLC) grade acetonitrile was acquired from Tedia Inc., Fairfield, $\mathrm{OH}$. Ultrapure water $(18.2 \mathrm{M} \Omega-\mathrm{cm})$ was obtained using a Millipore-Milli Q system, Millipore Corporation, Billerica, MA and was used to prepare all necessary solutions. Other chemical reagents were of analytical grade and used as received.

\subsection{Soil and groundwater samples}

The groundwater and soil samples were all collected from provinces throughout China in June 2013. Groundwater samples were all from wells used by local residents, and the soil samples were three representative soils from China (Acrisol, Luvisols and Phaeozems). The sampling procedure, preparation and selected properties of soil samples were listed in Support information.

\subsection{Photodegradation experiments}

A merry-go-round photochemical reactor (NBeT Electromechanical Plant, Beijing, China) was equipped with two sets of light irradiation system, (a) UV lamp irradiation $(\lambda>200 \mathrm{~nm})$ simulated by a $500 \mathrm{~W}$ high-pressure mercury lamp, and (b) simulated solar $(\lambda>300 \mathrm{~nm})$ irradiation via a $500 \mathrm{~W}$ xenon lamp with a $300 \mathrm{~nm}$ cut-off filter. The light source irradiation spectra are shown in Fig. 1 and the light intensities in the center of the reaction position were $41 \mathrm{~mW} / \mathrm{cm}^{-2}(200-500 \mathrm{~nm})$ and $35 \mathrm{~mW} / \mathrm{cm}^{-2}(300-2500 \mathrm{~nm})$ for the mercury lamp and xenon lamp, respectively (provided by the manufacturers). Quartz tubes were employed to contain the reaction solutions. During irradiation, aliquots of solution $(\sim 1.5 \mathrm{~mL})$ were withdrawn at periodic intervals for subsequent analysis. Unless noted otherwise, the initial concentration of DPAA for experiments was $20 \mathrm{mg} \mathrm{L}^{-1}$, which was slightly higher than the maximum concentration of DPAA $\left(\sim 15 \mathrm{mg} \mathrm{L}^{-1}\right)$ reported in water [3]. A $0.1 \mathrm{M}$ phosphate buffer and $\mathrm{Na}_{2} \mathrm{SO}_{4}$ were applied to adjust the $\mathrm{pH}$ value and ionic strength respectively. The ROS scavengers $\mathrm{NaN}_{3}$, $\mathrm{NaHCO}_{3}$ and superoxide dismutase (SOD) were added to the reaction solution to study the involvement of $\operatorname{ROS}\left(\right.$ e.g., $\left.{ }^{1} \mathrm{O}_{2},{ }^{\bullet} \mathrm{OH},{ }^{\bullet} \mathrm{O}_{2}{ }^{-}\right)$ in photodegradation [26]. Quantum yields of the direct photolysis of DPAA in pure water were measured with UV lamp irradiation in the wavelength range $200-425 \mathrm{~nm}$ (see detailed method in the Supporting information) and the photon rate was determined by potassium ferrioxalate actinometry [27], yielding a photon flux of $7.35 \times 10^{-5}$ Einstein $\mathrm{L}^{-1} \mathrm{~s}^{-1}$.

To illustrate the effects of common aqueous solutes $\left(\mathrm{HA}, \mathrm{Cl}^{-}\right.$, $\mathrm{NO}_{3}^{-}$and $\mathrm{NO}_{2}^{-}$) on the photodegradation kinetics of DPAA with different light sources, the representative reagents were dissolved within their normal environmental levels. In addition, dark controls shielded from light with aluminum foil were set up under the same experimental conditions simultaneously. Unless stated otherwise all treatments were conducted at $\mathrm{pH} 4.5$, which is the $\mathrm{pH}$ value of the $20 \mathrm{mg} \mathrm{L}^{-1}$ DPAA solution in MilliQ water. All treatments were set up in triplicate. A light screening factor $\left(S_{\lambda}\right)$ was applied to study the light screening effect, and its determination is detailed in the Supporting information.

\subsection{Electron paramagnetic resonance (epr) studies}

EPR spectroscopy was employed to identify the ROS radicals generated from the reaction solutions to further understand the role of ROS in the photodegradation mechanism of DPAA. The changes in peak intensity of free radicals were also recorded to indicate the changes in their concentrations [28]. 2,2,6,6-Tetramethyl-4-piperidone (TEMP, 95\%, Sigma-Aldrich) and 5,5-dimethyl-1-pyrroline-N-oxide (DMPO, 97\%, Sigma-Aldrich) 

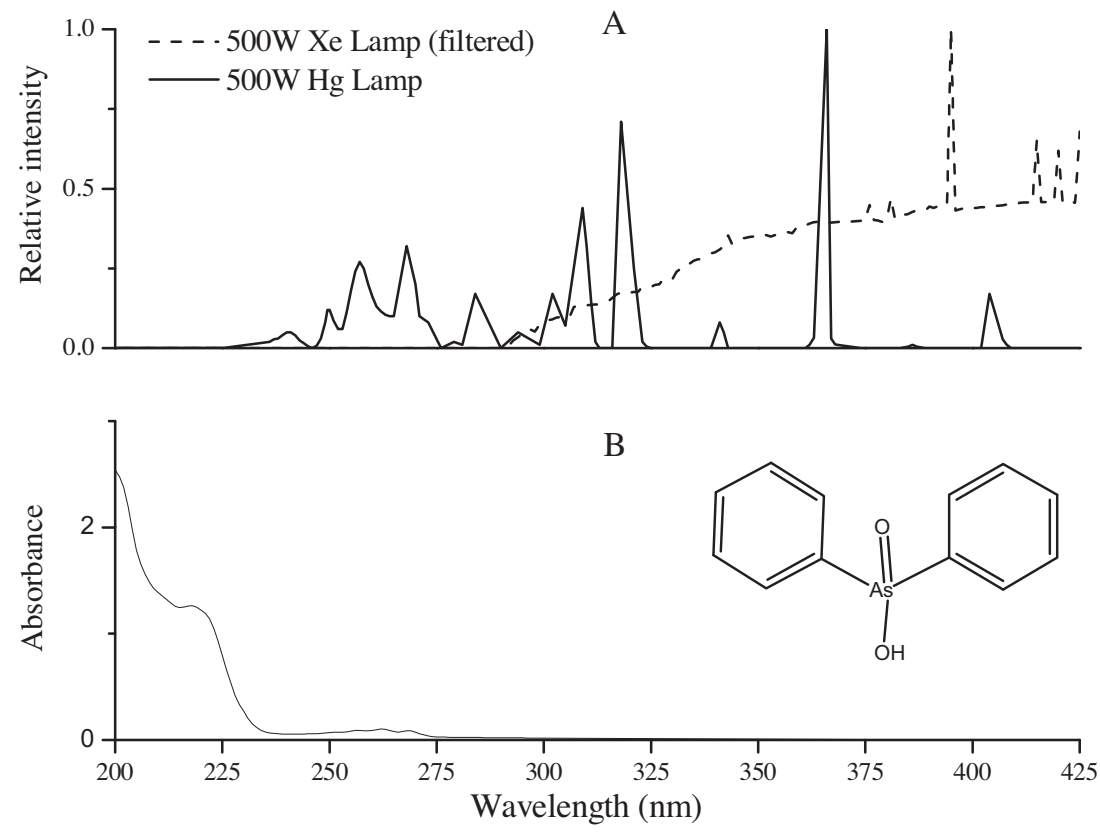

Fig. 1. (A) Emission spectra of two light sources used in this study. (B) Absorption spectrum of $20 \mathrm{mg} \mathrm{L}^{-1}$ DPAA in MilliQ water.

were used as the spin traps of ${ }^{1} \mathrm{O}_{2}$ and $\bullet \mathrm{OH} / \mathrm{O}_{2}{ }^{-\bullet}$, respectively. $200 \mu \mathrm{L}$ of reaction solution was mixed with $20 \mu \mathrm{l}$ of TEMP solution $(500 \mathrm{mM})$ or $100 \mu \mathrm{L}$ of reaction solution was mixed with $50 \mu \mathrm{L}$ of DMPO solution $(200 \mathrm{mM})$. The EPR spectra were recorded on a Bruker EMX 10/12 spectrometer (Billerica, MA) equipped with a $200 \mathrm{~W}$ mercury lamp as the irradiation light source $(\lambda>200 \mathrm{~nm})$ or the irradiation light was filtered with Pyrex glass to obtain $\lambda>290 \mathrm{~nm}$ light if needed. The EPR settings were: modulation frequency $100 \mathrm{kHz}$, modulation amplitude $2.00 \mathrm{G}$, microwave frequency $9.40 \mathrm{GHz}$ and power $5.10 \mathrm{~mW}$.

\subsection{Analytical methods}

The concentration of DPAA was determined by HPLC (Shimadzu, Japan) with a SPD-m20A detector (Shimadzu, Japan). The column was a Shimadzu VP-ODS $C_{18}$ column $(4.6 \times 150 \mathrm{~mm}, 5 \mu \mathrm{m})$. The sample injection volume was $10 \mu \mathrm{L}$ and the mobile phase was $19 \%$ acetonitrile and $81 \% 0.02 \mathrm{~mol} \mathrm{~L}^{-1}$ in $\mathrm{KH}_{2} \mathrm{PO}_{4}$ solution (acidified with phosphoric acid at $\mathrm{pH} 2.7$ ). The flow rate was $1 \mathrm{~mL} \mathrm{~min}^{-1}$ and the detector wavelength was $220 \mathrm{~nm}$. The organic intermediates were identified with an LCQ Fleet ion-trap mass spectrometer (Thermo Fisher Scientific, Waltham, MA) operated in negative-ion mode. PAA was quantified using a Thermo Fisher TSQ Quantum Access MAX triple stage quadrupole mass spectrometer equipped with an Ion $\mathrm{Max}^{\mathrm{TM}}$ source with negative HESI mode. Mass spectrometry detection was performed under the selective reaction monitoring (SRM) mode. The chromatographic separation conditions were as follows: a SunFire $C_{18}$ column $(4.6 \times 250 \mathrm{~mm}, 5 \mu \mathrm{m}$, Waters Corp., Milford, MA) was used. The mobile phase was $19 \%$ acetonitrile and $81 \%$ in $0.1 \%$ acetic acid solution $(\mathrm{pH}=2.7)$ at a flow rate of $0.8 \mathrm{~mL} \mathrm{~min}^{-1}$. The sample injection volume was $10 \mu \mathrm{L}$. The minimum detection limit of PAA was $0.1 \mathrm{mg} \mathrm{L}^{-1}$ and the recovery was $104.1 \%$. The inorganic arsenicals were analyzed by LC-ICP-MS $[29,30]$. The total organic carbon (TOC) of water samples was determined with a Shimadzu TOC- $\mathrm{V}_{\mathrm{CPH}}$ analyzer. Anions were analyzed with a Dionex ICS-3000 ion chromatograph (Dionex Corp., Sunnyvale, $\mathrm{CA}$ )

\subsection{Germination experiment}

Cucumber (Cucumis sativus L.) seeds are commonly used in phytotoxicity testing [31], were pur-chased from Yantai Dazhong Seed Co., Ltd. The average germination rates of the seeds were $>85 \%$ as shown in a trial study. Cucumber seeds were immersed in a $10 \%$ $\mathrm{NaClO}$ solution for $10 \mathrm{~min}$ and rinsed three times with DI-water to ensure surface sterility. The seeds were then soaked in MilliQ water and DPAA solution after different time of UVC irradiation $(0$, $1 \mathrm{~min}, 5 \mathrm{~min}, 30 \mathrm{~min}, 1 \mathrm{~h}$ and $2 \mathrm{~h}$ ), respectively, for $2 \mathrm{~h}$. One piece of filter paper was put into each $100 \times 15 \mathrm{~mm}$ Petri dish, and $5 \mathrm{~mL}$ of the solution mentioned above was added. Ten Seeds were evenly placed onto the filter paper. Petri dishes were then covered and placed in an incubator. There were four replicate dishes for each treatment. Germination was quantified when the bud length surpassed half of the seed length [32]. After 5 days in the dark under room temperature, more than $85 \%$ of the control seeds (only adding MilliQ water) germinated. Then, the germination was halted, seed germination rate was calculated, and seedling root length was measured.

\section{Results and discussion}

\subsection{Direct photolysis of DPAA at various $p H$ values}

No obvious loss of DPAA was found in the dark control or in the solution under simulated solar irradiation $(\lambda>300 \mathrm{~nm})$ which would be rationalized by the light absorbance of DPAA. As shown in Fig. 1, DPAA did not absorb light when $\lambda>300 \mathrm{~nm}$ and therefore could not undergo direct photolysis. In contrast, the direct photolysis of DPAA was rapid when exposed to UV lamp irradiation, due to the overlap of the DPAA UV-vis spectrum and the emission spectrum of the high-pressure $\mathrm{Hg}$ lamp $(\lambda>200 \mathrm{~nm})$. Loss of DPAA followed the exponential decay curve and thus pseudofirst-order kinetics well describe the photolytic kinetics of DPAA $\left(r^{2}>0.95\right)$. Under UV lamp irradiation, the wavelength-averaged $(200-300 \mathrm{~nm})$ quantum yield of DPAA photolysis was determined to be $0.067 \pm 0.002$.

Table 1 also shows the direct photodegradation rates of DPAA at various $\mathrm{pH}$ values. The most rapid rate was observed at $\mathrm{pH} 4.5$, 
Table 1

Photolytic rate constants $(k)$ of DPAA in different treatments under UV lamp irradiation $(\lambda>200 \mathrm{~nm})$. The data are means \pm standard errors $(n=3)$.

\begin{tabular}{lll}
\hline Matrix & \multicolumn{2}{l}{ DPAA $20 \mathrm{mg} \mathrm{L}^{-1}$} \\
\cline { 2 - 3 } & $(k \pm \mathrm{SD})^{*}\left(10^{-2} \mathrm{~s}^{-1}\right)$ & $r^{2}$ \\
\hline Pure water $^{\mathrm{a}}$ & $2.94 \pm 0.04 \mathrm{bc}$ & 0.998 \\
$\mathrm{pH} 3.0^{\mathrm{b}}$ & $2.77 \pm 0.20 \mathrm{~cd}$ & 0.954 \\
$\mathrm{pH} 4.5^{\mathrm{b}}$ & $3.11 \pm 0.16 \mathrm{~b}$ & 0.981 \\
$\mathrm{pH} 6.0^{\mathrm{b}}$ & $2.63 \pm 0.16 \mathrm{de}$ & 0.966 \\
$\mathrm{pH} 7.0^{\mathrm{b}}$ & $2.48 \pm 0.16 \mathrm{e}$ & 0.966 \\
$\mathrm{pH} 9.0^{\mathrm{b}}$ & $2.45 \pm 0.15 \mathrm{e}$ & 0.968 \\
Bubbling N$_{2}^{\mathrm{a}}(\mathrm{pH}=4.5)$ & $3.56 \pm 0.05 \mathrm{a}$ & 0.994 \\
Bubbling $_{2}{ }^{\mathrm{a}}(\mathrm{pH}=4.5)$ & $3.07 \pm 0.05 \mathrm{~b}$ & 0.998 \\
\hline
\end{tabular}

NB: different letters indicate significant difference among treatments $(P>0.05)$.

a DPAA was dissolved in MilliQ water.

b DPAA was dissolved in $0.1 \mathrm{M}$ phosphate buffer.

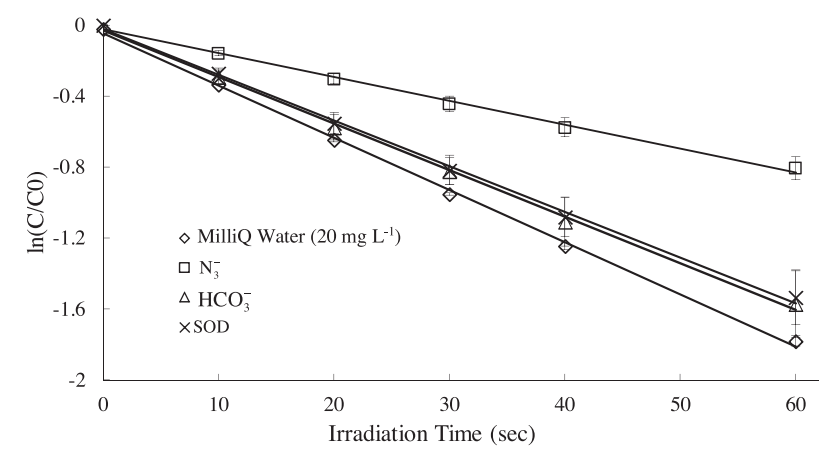

Fig. 2. Effect of ROS scavengers on the photodegradation of DPAA. The concentration of DPAA was $20 \mathrm{mg} \mathrm{L}^{-1}$. The concentrations of $\mathrm{NaN}_{3}, \mathrm{NaHCO}_{3}$ and SOD were $100 \mathrm{mg} \mathrm{L}^{-1}, 100 \mathrm{mg} \mathrm{L}^{-1}$ and 400 unit ml$^{-1}$, respectively. Error bars are the standard deviations of tripicate determinations.

and photolysis rates at the $\mathrm{pH}$ over the pKa of DPAA ( $\mathrm{pKa}=5.25$ [6]) were slower than the ones at the $\mathrm{pH}$ under the pKa. According to the UV-vis spectra of DPAA at various $\mathrm{pH}$ values from 3.0 to 9.0 (Fig. S1), the absorbance of DPAA at pH 4.5 was the highest than rest of them and this may contribute to a more rapid photodegradation rate of DPAA. It suggested the photodegradation rates of DPAA were correlated with its $\mathrm{pH}$-dependent molar absorptivities, which were determined by the ratio of the molecular form and deprotonated form of DPAA.

\subsection{DPAA photolytic mechanism}

The contributions of both direct and indirect reactions to the photolysis of DPAA were studied. The results show that direct photodegradation was the dominant reaction pathway.

The reactive oxygen species (ROS) quenching experiments were designed firstly to show the roles of different ROS in the photolysis of DPAA (Fig. 2). The addition of $\mathrm{NaN}_{3}$ (a quencher of singlet oxygen and hydroxyl radicals) retarded the photolytic rate. In contrast, bicarbonate (a quencher of the hydroxyl radical) and SOD (a quencher of superoxide radicals) had little effect on the reaction kinetics in this study. Combined with the EPR measurement, the occurrence of ${ }^{1} \mathrm{O}_{2}$ in the DPAA solution exposed to UV irradiation was also confirmed (Fig. S2e). Under UV lamp irradiation the DPAA solution containing TEMP displayed a significant 1:1:1 triple signal, the characteristic spectrum of TEMP-adduct with singlet oxygen [33]. In contrast, there was no signal in the DPAA solution containing DMPO with or without irradiation (Fig. S2b and d). Furthermore, the $\mathrm{NaN}_{3}$ in the irradiation solution can suppress the strength of the TEMP-adduct signal (Fig. S2f) and in contrast the addition of isopropanol, a quencher of hydroxyl radicals, had no effect on the strength of the triple signal (Fig. S2g).

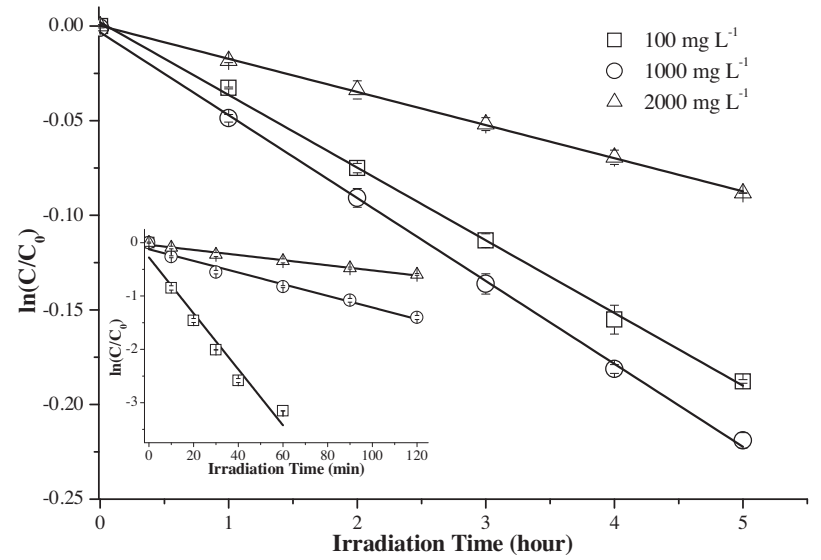

Fig. 3. Effect of rose rengal (RB) on DPAA photolysis under visible light irradiation. The initial concentration of DPAA was $20 \mathrm{mg} \mathrm{L}^{-1}$. Inset are the photodegradation kinetics of different concentrations of RB under same light irradiation at the same time. Error bars are the standard deviations of tripicate determinations.

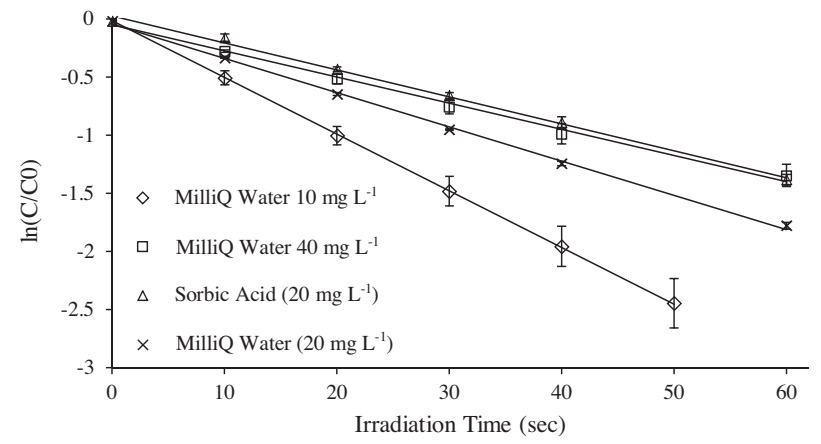

Fig. 4. Effect of sorbic acid and initial concentrations on DPAA photolysis under $\mathrm{Hg}$ lamp light irradiation. Error bars are the standard deviations of tripicate determinations.

Considering the effective retardation by $\mathrm{NaN}_{3}$, it seems that the indirect photolysis via ${ }^{1} \mathrm{O}_{2}$ oxidation would have taken up a large proportion of DPAA photodegradation. However, further experiments with two well-known ${ }^{1} \mathrm{O}_{2}$ generation systems (humic acid and Rose Bengal irradiated by simulated solar light) have found the reaction rate between DPAA and pure ${ }^{1} \mathrm{O}_{2}$ to be much slower than expected. Under the same simulated solar irradiation, DPAA was not removed from the solution containing HA, and decayed only very slowly in that containing RB (Fig. 3 ). In the RB solution the fastest degradation rate constant of DPAA was only $(4.38 \pm 0.06) \times 10^{-2} \mathrm{~h}^{-1}$, several orders of magnitude smaller than that observed in MilliQ water. In addition, the second order rate constant $\left(k^{1} \mathrm{O}_{2}\right.$, DPAA) for the reaction between DPAA and ${ }^{1} \mathrm{O}_{2}$ was also determined as $1.32 \times 10^{6} \mathrm{M}^{-1} \mathrm{~s}^{-1}$. Azide has been reported to be a good quencher not only for ${ }^{1} \mathrm{O}_{2}$, but also for the excited state of some photosensitizers [34-36]. In this case, quenching excitedstate DPAA (such as triplet-state DPAA) by $\mathrm{NaN}_{3}$ might contribute to the clear inhibitory effect on the DPAA photolytic rate under UV irradiation, not by quenching ${ }^{1} \mathrm{O}_{2}$. In conclusion, ${ }^{1} \mathrm{O}_{2}$ was the only one ROS generated during the photodegradation of DPAA under UV-C irradiation but had little effect on the DPAA photodegradation rate.

The involvement of triplet state DPAA $\left({ }^{3} \mathrm{DPAA}^{*}\right)$ in the direct photolysis of DPAA was also studied by adding the triplet state quencher sorbic acid to the reaction solution. As shown in Fig. 4, the presence of sorbic acid retarded the direct photodegradation of DPAA. This result indicates that the ${ }^{3} \mathrm{DPAA}^{*}$ was key to DPAA 


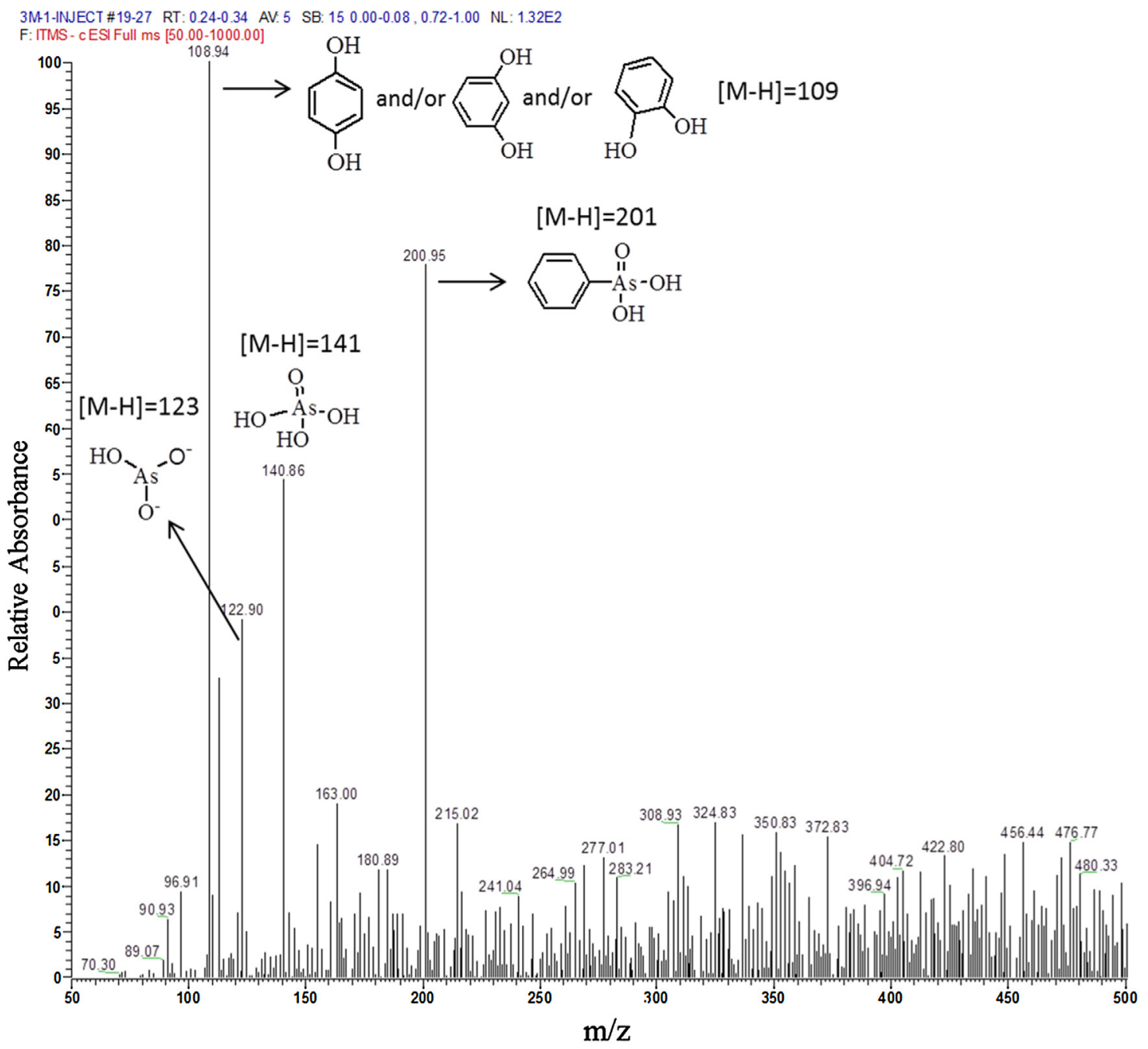

Fig. 5. ESI-MS spectrum showing possible photolytic degradation products of DPAA.

direct photolysis, and that it can be formed through an intersystem crossing (ISC) process from singlet-state DPAA $\left({ }^{1} \mathrm{DPAA}^{*}\right)$.

Further study shows that dissolved oxygen (DO) in water also affected the photodegradation rate of DPAA, and this result may be attributed to ${ }^{3} \mathrm{DPAA}^{*}$ quenching by DO. As shown in Table 1, bubbling $\mathrm{N}_{2}$ through the DPAA solution promoted the photolytic rate. However, bubbling $\mathrm{O}_{2}$ through the DPAA solution had no effect on the reaction rate. This result is consistent with previous reports [37] and may be explained by DO acting as a quencher of the excited state of DPAA (e.g., ${ }^{3}$ DPAA $^{*}$ ) and then generating ${ }^{1} \mathrm{O}_{2}$ through energy transfer. When oxygen is removed, DPAA can decompose through direct photolysis more quickly without ${ }^{3} \mathrm{DPAA}^{*}$ scavenger.

In addition, the direct photolysis rate of DPAA was also found to be concentration-dependent. As shown in Fig. 4, the degradation rates of DPAA decreased with its increasing initial concentration. The results imply that the excited-state DPAA can also be quenched by itself.

Based on the results above, under UV-C irradiation DPAA can undergo direct photolysis as follows:

$$
\begin{aligned}
& \text { DPAA } \stackrel{h v}{\rightarrow}{ }^{1} \mathrm{DPAA}^{*} \stackrel{\mathrm{ISC}_{3}}{\rightarrow} \mathrm{DPAA}^{*} \rightarrow \text { Products } \\
& \text { DPAA } \stackrel{h v}{\rightarrow}{ }^{D P A A} \stackrel{*}{*} \mathrm{ISC}_{3} \mathrm{DPAA}^{*} \rightarrow \text { Products }
\end{aligned}
$$

During this process, ${ }^{1} \mathrm{O}_{2}$ was generated but the indirect photolysis was so slow that it can be ignored.

\subsection{Phototransformation pathway and total arsenic mass} balance

The main intermediates in photodegradation were identified. An ESI-MS spectrum of the photolysis of DPAA happening in MilliQ water after $1 \mathrm{~min}$ is shown in Fig. 5. According to the molecular weight, the ion (in negative ion mode) at $m / z 200.95$ represented PAA. Ions at $m / z 140.9$ and 122.9 were concluded to be arsenate and arsenite, respectively. The ion at $m / z 108.9$ corresponded to dihydroxybenzenes.

The occurrence of different arsenic species was noted carefully because of the relatively high toxicity of elemental arsenic. PAA was identified by ESI-MS (Fig. S3). Inorganic arsenicals were also confirmed by HPLC-ICP-MS (Fig. S4). A balance for total arsenic during the whole irradiation period ( $30 \mathrm{~min}$ ) was calculated to fully understand its fate (Table 2). The concentration of PAA increased at the early stages of photolysis and then dissipated within $30 \mathrm{~min}$. In contrast, inorganic As increased with increasing irradiation time. Under UV lamp irradiation, DPAA was transformed into PAA at the initial stages and then decomposed completely into inorganic arsenicals. The occurrence of resorcinol and phenol was confirmed by HPLC measurement, and the TOC in the photolysis solution was found to reduce during the photodegradtion of DPAA (shown in Fig. S5). The decrease of TOC suggested that intermediates of the photolysis of DPAA could be mineralized. Phenol was reported that it could be converted into $\mathrm{CO}_{2}$ under the UVC treatment $[38,39]$. A proposed 
Table 2

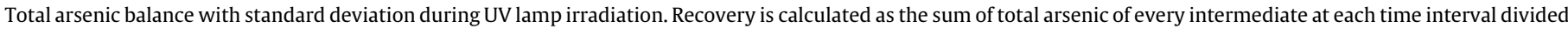
by the total arsenic in DPAA at the start.

\begin{tabular}{|c|c|c|c|c|c|}
\hline \multirow[t]{3}{*}{ Arsenic species } & \multicolumn{5}{|c|}{ Time after UV lamp irradiation (min) } \\
\hline & 0 & 0.5 & 1 & 5 & 30 \\
\hline & \multicolumn{5}{|l|}{ mg As kg-1 } \\
\hline DPAA & $6.23 \pm 0.83$ & $2.27 \pm 0.23$ & $0.91 \pm 0.14$ & $0.02 \pm 0.002$ & 0 \\
\hline PAA & 0 & $3.32 \pm 0.29$ & $3.62 \pm 0.32$ & $0.69 \pm 0.26$ & 0 \\
\hline $\mathrm{As}(\mathrm{III})$ & 0 & $0.28 \pm 0.23$ & $0.33 \pm 0.20$ & $1.21 \pm 0.02$ & $2.30 \pm 0.90$ \\
\hline $\mathrm{As}(\mathrm{V})$ & 0 & $0.63 \pm 0.02$ & $1.44 \pm 0.03$ & $4.17 \pm 0.23$ & $3.93 \pm 0.34$ \\
\hline Recovery & & $104 \%$ & $101 \%$ & $98 \%$ & $100 \%$ \\
\hline
\end{tabular}

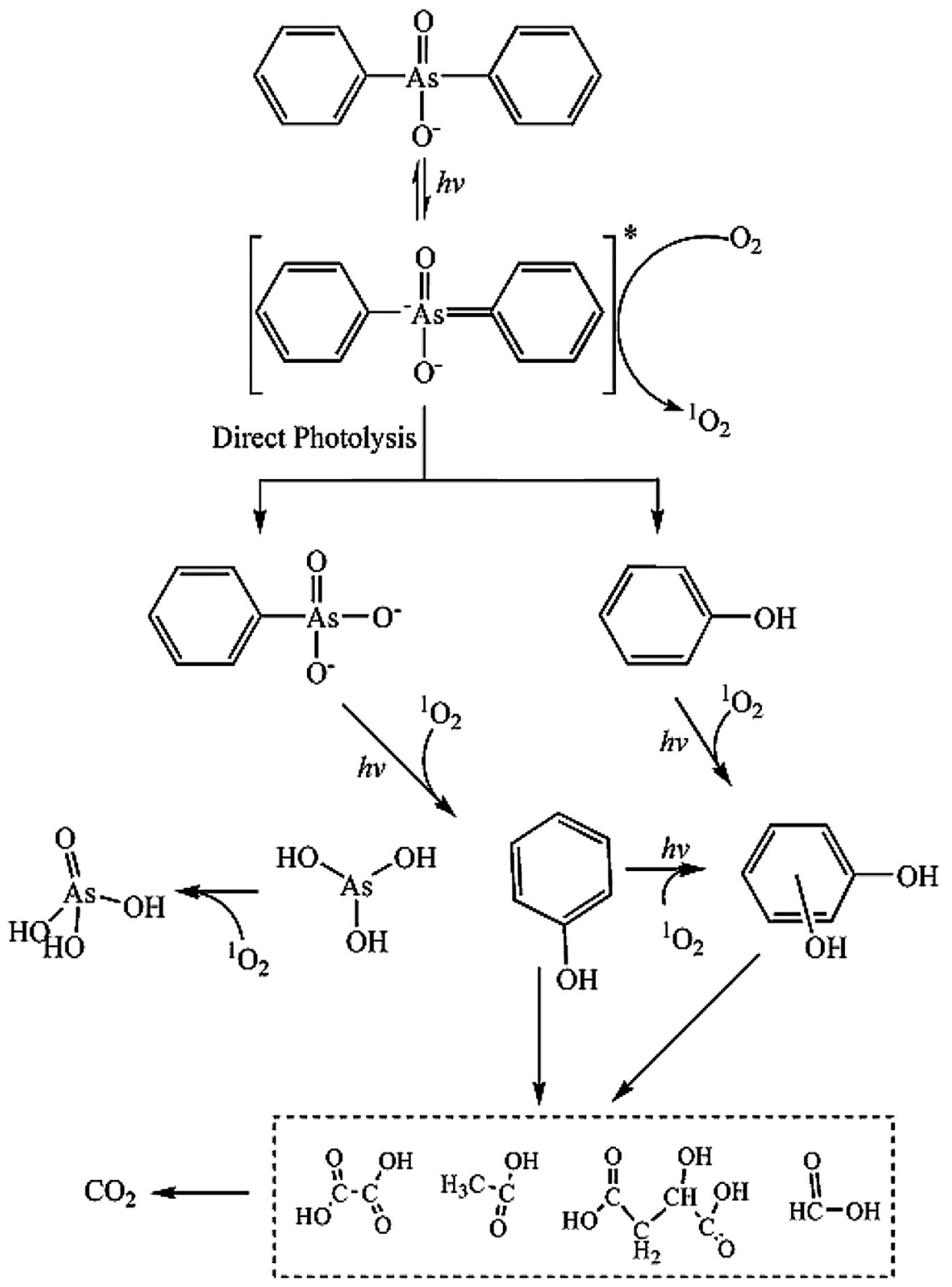

Scheme 1. Proposed pathway for the photodegradation of DPAA.

phototransformation process was established based on the results (Scheme 1).

\subsection{DPAA photolysis in natural water}

The photolysis of DPAA was also conducted in two types of natural water affected by the soil environment. One group was soil leachates and the other was groundwater. DPAA was also found to be photodegraded quickly in all natural water samples under the UV lamp irradiation (Table 3). The results also show that in soil leachates the photolytic rate constants were significantly negatively correlated with total organic carbon (TOC) $(r>0.976)$, possibly due to higher TOC contents in the soil leachates. In groundwater the photolytic rate constants of DPAA were negatively correlated only with $\mathrm{NO}_{3}{ }^{-}(r>0.968)$, the content of which was higher than those of other common solutes. It can be inferred 
Table 3

Selected properties and photodegradation rate constants $(k)$ with standard deviation in soil leachates and groundwaters.

\begin{tabular}{|c|c|c|c|c|c|c|c|}
\hline Category & No. & $(k \pm \mathrm{SD})^{*} 10^{-2}\left(\mathrm{~s}^{-1}\right)$ & $\mathrm{pH}$ & $\mathrm{TOC}\left(\mathrm{C} \mathrm{mg} \mathrm{L}^{-1}\right)$ & $\mathrm{NO}_{3}{ }^{-}\left(\mathrm{mg} \mathrm{L}^{-1}\right)$ & $\mathrm{Cl}^{-}\left(\mathrm{mg} \mathrm{L}^{-1}\right)$ & Sample location (province) \\
\hline \multirow[t]{6}{*}{ Soil leachate } & 1 & $2.22 \pm 0.03$ & 5.01 & 14.18 & 0.62 & 0.41 & Jiangxi \\
\hline & 2 & $1.78 \pm 0.14$ & 4.68 & 49.10 & 4.56 & 0.66 & Jiangxi \\
\hline & 3 & $2.13 \pm 0.12$ & 4.52 & 15.82 & 2.52 & 1.23 & Jiangxi \\
\hline & 4 & $1.97 \pm 0.03$ & 6.23 & 37.39 & 3.40 & 1.43 & Jiangxi \\
\hline & 5 & $1.64 \pm 0.16$ & 5.38 & 19.67 & 1.67 & 1.55 & Jiangsu \\
\hline & 6 & $1.18 \pm 0.08$ & 6.63 & 50.50 & 1.29 & 4.40 & Heilongjiang \\
\hline \multirow[t]{5}{*}{ Groundwater } & 7 & $2.02 \pm 0.07$ & 7.71 & 5.44 & 2.60 & 38.91 & Anhui \\
\hline & 8 & $1.72 \pm 0.11$ & 7.81 & 8.50 & 51.40 & 14.13 & Beijing city \\
\hline & 9 & $2.09 \pm 0.03$ & 8.13 & 3.93 & 0.58 & 29.52 & Jiangsu \\
\hline & 10 & $1.62 \pm 0.05$ & 7.86 & 4.86 & 48.80 & 17.61 & Jiangxi \\
\hline & 11 & $1.58 \pm 0.13$ & 7.62 & 12.21 & 76.10 & 67.74 & Anhui \\
\hline
\end{tabular}

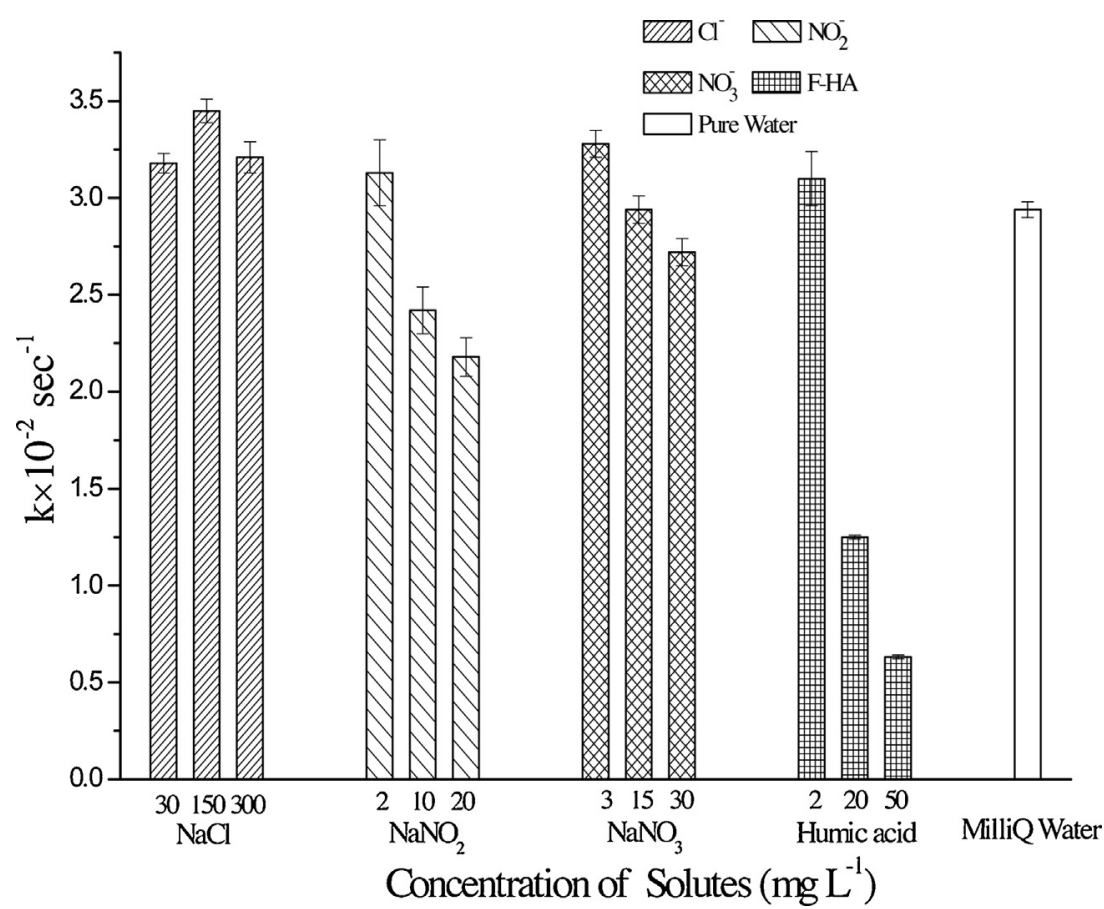

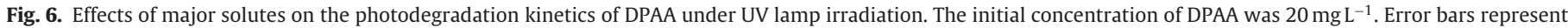
the standard deviations.

that the aquatic photolytic rate of DPAA was controlled by soluble components in the reaction solution.

\subsection{Effect of main solutes on DPAA photolysis}

The effects of common aquatic solutes on DPAA photolysis at the same $\mathrm{pH}$ value were investigated. The results show that $\mathrm{NO}_{3}{ }^{-}$, $\mathrm{NO}_{2}{ }^{-}$and $\mathrm{HA}$ had concentration-dependent effects on the DPAA photolytic rate which decayed with increasing solute concentrations, while the presence of $\mathrm{Cl}^{-}$promoted the reaction rate (Fig. 6).

The accelerating effect caused by $\mathrm{Cl}^{-}$may be explained by this halide ion enhancing the concentration of triplet-state DPAA. Glover and Rosario-Ortiz [40] found that halides can enhance the intersystem crossing of DOM from singlet state to triplet state, thus increasing the steady state concentration of triplet-state DOM. In addition, the increased generation of ${ }^{1} \mathrm{O}_{2}$ also confirms the enhancement of triplet-state DOM because the occurrence of ${ }^{1} \mathrm{O}_{2}$ was through the quenching of ${ }^{3} \mathrm{DOM}^{*}$ by dissolved oxygen. In our study the EPR experiment also found that the addition of $\mathrm{Cl}^{-}$ increased the ${ }^{1} \mathrm{O}_{2}$ signature (Fig. S2h). This shows that the ${ }^{3} \mathrm{DPAA}^{*}$ concentration increased, and thus the direct photolytic rate of DPAA was enhanced.
It is worth mentioning that Parker et al. [41] found that the triplet-state natural organic matter $\left({ }^{3} \mathrm{NOM}^{*}\right)$ lifetime could be prolonged by the effect of IS. Here, in this study, the addition of $\mathrm{PO}_{4}{ }^{3-}$ and $\mathrm{SO}_{4}{ }^{2-}$ had little effect on DPAA photolytic rate (data not shown). Therefore, the positive effect of $\mathrm{Cl}^{-}$on the DPAA photolytic rate was ion-dependent only.

To elucidate the effects of $\mathrm{NO}_{3}{ }^{-}, \mathrm{NO}_{2}{ }^{-}$and $\mathrm{HA}$ on the DPAA photolytic rate, the "light screening factor" $\left(S_{\lambda}\right)$ was introduced to estimate an upper-limit expected DPAA direct photolytic rate in any given solution [42]. As shown in Table 4, all of the solutes should have enhanced the direct photolysis rate of DPAA at every given level, but they all inhibited the photolytic rate of DPAA much less than expected. In addition, Fig. S2 $(1, \mathrm{k}, \mathrm{m})$ also shows that the presence of these particular solutes lowered the signal intensity of ${ }^{1} \mathrm{O}_{2}$, in other words, decreased the concentration of ${ }^{3} \mathrm{DPAA}^{*}$. Considering the insignificance of indirect photolysis by ROS in the photodegradation of DPAA under UV-C irradiation, the results imply that the production of ${ }^{3} \mathrm{DPAA}^{*}$ was suppressed by these solutes which can compete with DPAA in UV-C adsorption. According to the inhibition efficiency shown in Table 4, the inhibitory capabilities of these specific solutes on excited-state DPAA were as follows from small to large: $\mathrm{NO}_{3}{ }^{-}<\mathrm{NO}_{2}{ }^{-}<\mathrm{HA}$. 
Table 4

Estimated direct photolytic rate constants $\left(k_{\text {est }}\right)$ of DPAA in the presence of various solutes at different levels.

\begin{tabular}{|c|c|c|c|c|c|}
\hline Solute & Concentration $\left(\mathrm{mg} \mathrm{L}^{-1}\right)$ & $k_{\text {obs }}\left(k \times 10^{-2} \mathrm{~s}^{-1}\right)$ & $S_{\lambda(225-275)}$ & $k_{\text {est }}\left(k \times 10^{-2} \mathrm{~s}^{-1}\right)$ & Inhibition efficiency(\%) \\
\hline MilliQ water & 0 & 2.94 & - & - & - \\
\hline \multirow[t]{3}{*}{ Humic acid } & 2 & 3.10 & 5.67 & 16.7 & $81.4 \%$ \\
\hline & 20 & 1.25 & 99.1 & 291 & $99.6 \%$ \\
\hline & 50 & 0.63 & 266 & 783 & $99.9 \%$ \\
\hline \multirow[t]{3}{*}{$\mathrm{NO}_{2}^{-}$} & 2 & 3.13 & 2.05 & 6.02 & $48.0 \%$ \\
\hline & 10 & 2.42 & 6.31 & 18.6 & $87.0 \%$ \\
\hline & 20 & 2.18 & 10.0 & 29.4 & $92.6 \%$ \\
\hline \multirow[t]{3}{*}{$\mathrm{NO}_{3}^{-}$} & 3 & 3.28 & 1.73 & 5.10 & $35.7 \%$ \\
\hline & 15 & 2.94 & 2.92 & 8.59 & $65.8 \%$ \\
\hline & 30 & 2.72 & 5.27 & 15.5 & $82.4 \%$ \\
\hline
\end{tabular}

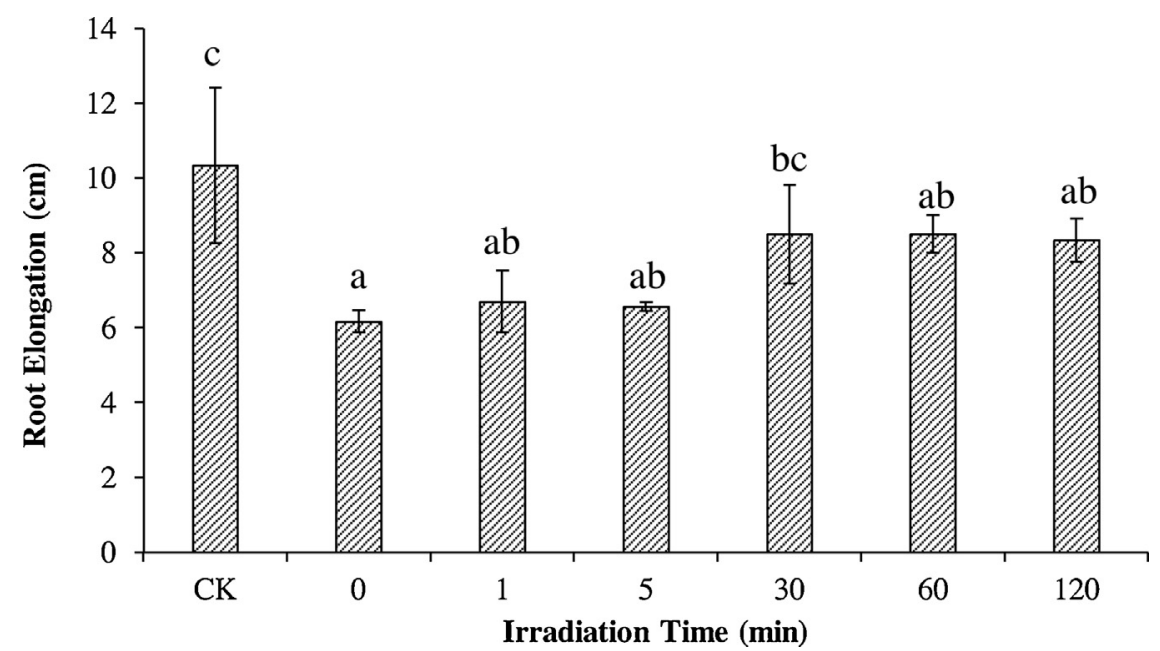

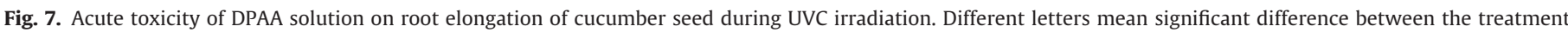
means $(p<0.05)$.

\subsection{Toxicity of photolysis solution}

Cucumber seedling was applied to evaluate the toxicity of DPAA and its photolytic intermediates. All reaction solutions had no statistically significant effect on the germination rates of cucumber seeds, which were more than $85 \%$. Fig. 7 shows all treatments inhibited the root elongation of cucumber seeds. The reduction of root growth in initial DPAA solution $\left(20 \mathrm{mg} \mathrm{L}^{-1}\right)$ and its $1 \mathrm{~min}$ and 5 min photolysis solutions was more than it in the reaction solutions after $30 \mathrm{~min}$ UVC irradiation. The toxicity of photolysis solution could contribute to the combination of DPAA, organic and inorganic arsenic species and phenol compounds [21]. At the initial photolysis stage, all these reactant and products existed in the solution causing a higher toxicity. After $30 \mathrm{~min}$ UVC irradiation, some phenol compounds could be mineralized reducing the toxicity.

\section{Conclusions}

The present study has shown that DPAA can be degraded efficiently under UV-C irradiation. This photodegradtion process depended mainly on direct photolysis via excited-state DPAA. The ${ }^{1} \mathrm{O}_{2}$ was generated in this process but played an insignificant role in DPAA photolysis. Furthermore, common solutes such as $\mathrm{Cl}^{-}, \mathrm{NO}_{2}{ }^{-}$, $\mathrm{NO}_{3}{ }^{-}$and $\mathrm{HA}$ can influence the DPAA photolytic rate by controlling the existence of its excited state. Last but not least, the main end-product of the photodegradation of DPAA was identified as inorganic arsenic species.

Although soil is the main pool for DPAA and other arsenical chemical weapon residuals, its poor capacity to retain such contaminants allows that DPAA can move downward easily $[43,44]$. Soil leachates and groundwater will bear the brunt of DPAA discharged into the environment.

Comparing to biodegradation of DPAA, which is timeconsuming, limited degradation capacity and poor inorganicarsenic yield $[6,11,13]$, the photodegradation of DPAA can be a promising treatment for DPAA decontamination. DPAA can degrade in a short time at a relatively high concentration $\left(20 \mathrm{mg} \mathrm{L}^{-1}\right.$ of DPAA is much higher than $5 \mathrm{mg} \mathrm{L}^{-1}$ of it reported in biodegradation studies) under UV-C irradiation. In addition, the UV treatment is a mature technology for water purifying and has been applied in practices widely [19,45-47]. Finally, through UVC treatment DPAA decomposed entirely into inorganic arsenic species, which can be readily absorbed by hyperaccumulator plant species such as Pteris vittata $\mathrm{L}$. [48] or removed by various adsorbents [49-51].

The future studies should consider the application of UVC treatment in real practice for the decontamination of DPAA-like residues from chemical weapons. To achieve the aim, the fluence-based rate constant could be applied to study the photodegradtion. This rate constant is a function of UV-dose, and thus can guide the requirement of UVC irradiation energy for specific treatment [19].

\section{Acknowledgements}

This work was supported by the National Natural Science Foundation of China (Nos 41230858, 41171248, 41571310). The authors would like to thank Professor Lena Q. Ma and Dr. Jinghua Reng at Nanjing University and Dr. Ying Liu at Yantai Institute of Coastal Zone Research, Chinese Academy of Sciences, for help with arsenic analysis. 


\section{Appendix A. Supplementary data}

Supplementary data associated with this article can be found, in the online version, at http://dx.doi.org/10.1016/j.jhazmat.2016.01. 049.

\section{References}

[1] M. Leermakers, W. Baeyens, M. De Gieter, B. Smedts, C. Meert, H.C. De Bisschop, R. Morabito, P. Quevauviller, Toxic arsenic compounds in environmental samples: speciation and validation, TrAC Trend Anal. Chem. 25 (2006) 1-10.

[2] J.A. Tornes, A.M. Opstad, B.A. Johnsen, Determination of organoarsenic warfare agents in sediment samples from Skagerrak by gas chromatography-mass spectrometry, Sci. Total Environ. 356 (2006) 235-246.

[3] T. Wada, E. Nagasawa, S. Hanaoka, Simultaneous determination of degradation products related to chemical warfare agents by high-performance liquid chromatography/mass spectrometry, Appl. Organomet. Chem. 20 (2006) 573-579.

[4] M. Hempel, B. Daus, C. Vogt, H. Weiss, Natural attenuation potential of phenylarsenicals in anoxic groundwaters, Environ. Sci. Technol. 43 (2009) 6989-6995.

[5] T. Bausinger, J. Preuss, Environmental remnants of the first World War: soil contamination of a burning ground for arsenical ammunition, B Environ. Contam. Tox. 74 (2005) 1045-1052.

[6] K. Nakamiya, T. Nakayama, H. Ito, J.S. Edmonds, Y. Shibata, M. Morita, Degradation of arylarsenic compounds by microorganisms, Fems. Microbiol. Lett. 274 (2007) 184-188.

[7] M. Ishizaki, T. Yanaoka, M. Nakamura, T. Hakuta, S. Ueno, M. Komura, M. Shibata, T. Kitamura, A. Honda, M. Doy, K. Ishii, A. Tamaoka, N. Shimojo, T. Ogata, E. Nagasawa, S. Hanaoka, Detection of bis(diphenylarsine) oxide diphenylarsinic acid and phenylarsonic acid, compounds probably derived from chemical warfare agents, in drinking well water, J. Health Sci. 51 (2005) $130-137$.

[8] B. Daus, M. Hempel, R. Wennrich, H. Weiss, Concentrations and speciation of arsenic in groundwater polluted by warfare agents, Environ. Pollut. 158 (2010) 3439-3444.

[9] K. Ishii, A. Tamaoka, F. Otsuka, N. Iwasaki, K. Shin, A. Matsui, G. Endo, Y. Kumagai, T. Ishii, S. Shoji, T. Ogata, M. Ishizaki, M. Doi, N. Shimojo, Diphenylarsinic acid poisoning from chemical weapons in Kamisu, Japan Ann. Neurol. 56 (2004) 741-745.

[10] T. Arao, Y. Maejima, K. Baba, Uptake of aromatic arsenicals from soil contaminated with diphenylarsinic acid by rice, Environ. Sci. Technol. 43 (2009) 1097-1101.

[11] N. Harada, K. Takagi, K. Baba, K. Fujii, A. Iwasaki, Biodegradation of diphenylarsinic acid to arsenic acid by novel soil bacteria isolated from contaminated soil, Biodegradation 21 (2010) 491-499.

[12] M. Kohler, K. Hofmann, F. Volsgen, K. Thurow, A. Koch, Bacterial release of arsenic ions and organoarsenic compounds from soil contaminated by chemical warfare agents, Chemosphere 42 (2001) 425-429.

[13] L. Guan, S. Hisatomi, K. Fujii, M. Nonaka, N. Harada, Enhanced transformation of diphenylarsinic acid in soil under sulfate-reducing conditions, J. Hazard. Mater. 241 (2012) 355-362.

[14] O.S. Keen, I. Ferrer, E.M. Thurman, K.G. Linden, Degradation pathways of lamotrigine under advanced treatment by direct UV photolysis, hydroxyl radicals, and ozone, Chemosphere 117 (2014) 316-323.

[15] C.M. Glover, S.P. Mezyk, K.G. Linden, F.L. Rosario-Ortiz, Photochemical degradation of Corexit components in ocean water, Chemosphere 111 (2014) 596-602.

[16] K.P. Mangalgiri, A. Adak, L. Blaney, Organoarsenicals in poultry litter: detection, fate, and toxicity, Environ. Int. 75 (2015) 68-80.

[17] A.J. Bednar, J.R. Garbarino, I. Ferrer, D.W. Rutherford, R.L. Wershaw, J.F. Ranville, T.R. Wildeman, Photodegradation of roxarsone in poultry litter leachates, Sci. Total Environ. 302 (2003) 237-245.

[18] K. Jaworek, M. Czaplicka, L. Bratek, Decomposition of phenylarsonic acid by AOP processes: degradation rate constants and by-products, Environ. Sci. Pollut. Res. Int. 21 (2014) 11917-11923.

[19] A. Adak, K.P. Mangalgiri, J. Lee, L. Blaney, UV irradiation and UV- $\mathrm{H}_{2} \mathrm{O}_{2}$ advanced oxidation of the roxarsone and nitarsone organoarsenicals, Water Res. 70 (2015) 74-85.

[20] M. Czaplicka, L. Bratek, K. Jaworek, J. Bonarski, S. Pawlak, Photo-oxidation of $p$-arsanilic acid in acidic solutions: kinetics and the identification of by-products and reaction pathways, Chem. Eng. J. 243 (2014) 364-371

[21] X.D. Zhu, Y.J. Wang, C. Liu, W.X. Qin, D.M. Zhou, Kinetics, intermediates and acute toxicity of arsanilic acid photolysis, Chemosphere 107 (2014) 274-281.

[22] Y.P. Chin, P.L. Miller, L.K. Zeng, K. Cawley, L.K. Weavers, Photosensitized degradation of bisphenol a by dissolved organic matter, Environ. Sci. Technol. 38 (2004) 5888-5894

[23] S. Chiron, C. Minero, D. Vione, Photodegradation processes of the antiepileptic drug carbamazepine, relevant to estuarine waters, Environ. Sci.Technol. 40 (2006) 5977-5983.
[24] Y.F. Ji, L. Zhou, Y. Zhang, C. Ferronato, M. Brigante, G. Mailhot, X. Yang, J.M. Chovelon, Photochemical degradation of sunscreen agent 2-phenylbenzimidazole-5-sulfonic acid in different water matrices, Water Res, 47 (2013) 5865-5875.

[25] A. Rodrigues, A. Brito, P. Janknecht, M.F. Proenca, R. Nogueira, Quantification of humic acids in surface water: effects of divalent cations, $\mathrm{pH}$, and filtration, J. Environ. Monit. 11 (2009) 377-382.

[26] Z.H. Xu, C.Y. Jing, F.S. Li, X.G. Meng, Mechanisms of photocatalytical degradation of monomethylarsonic and dimethylarsinic acids using nanocrystalline titanium dioxide, Environ. Sci.Technol. 42 (2008) 2349-2354.

[27] C.G. Hatchard C. A. Parker A new sensitive chemical actinometer 2. Potassium ferrioxalate as a standard chemical actinometer, Proc. R. Soc. Lon. A 235 (1956) 518-536.

[28] Y. Shang, C.Y. Chen, Y. Li, J.C. Zhao, T. Zhu, Hydroxyl radical generation mechanism during the redox cycling process of 1,4-naphthoquinone, Environ. Sci. Technol. 46 (2012) 2935-2942

[29] P.N. Williams, A. Villada, C. Deacon, A. Raab, J. Figuerola, A.J. Green, J. Feldmann, A.A. Meharg Greatly enhanced arsenic shoot assimilation in rice leads to elevated grain levels compared to wheat and barley, Environ. Sci. Technol. 41 (2007) 6854-6859.

[30] C. Wu, Z.H. Ye, W.S. Shu, Y.G. Zhu, M.H. Wong, Arsenic accumulation and speciation in rice are affected by root aeration and variation of genotypes, J. Exp. Bot. 62 (2011) 2889-2898.

[31] R.C. Zhang, H.B. Zhang, C. Tu, X.F. Hu, L.Z. Li, Y.M. Luo, P. Christie, Phytotoxicity of ZnO nanoparticles and the released Zn(II) ion to corn (Zea mays L.) and cucumber (Cucumis sativus L.) during germination, Environ. Sci. Pollut. Res. Int. 22 (2015) 11109-11117.

[32] Z.Y. Wang, X.Y. Xie, J. Zhao, X.Y. Liu, W.Q. Feng, J.C. White, B.S. Xing, Xylemand Phloem-Based Transport of CuO Nanoparticles in Maize (Zea mays L.), Environ. Sci. Technol. 46 (2012) 4434-4441.

[33] R. Long, K.K. Mao, X.D. Ye, W.S. Yan, Y.B. Huang, J.Y. Wang, Y. Fu, X.S. Wang, X.J. Wu, Y. Xie, Y.J. Xiong, Surface facet of palladium nanocrystals: a key parameter to the activation of molecular oxygen for organic catalysis and cancer treatment, J. Am. Chem. Soc. 135 (2013) 3200-3207.

[34] N. Hasty, P.B. Merkel, P. Radlick, D.R. Kearns, Role of azide in singlet oxygen reactions - reaction of azide with singlet oxygen, Tetrahedron Lett. (1972) 49

[35] K. Reszka, R.D. Hall, C.F. Chignell, Quenching of the excited-states of 2-phenylbenzoxazole by azide anion-fluorescence and electron-spin-resonance study, Photochem. Photobiol. 40 (1984) 707-713.

[36] E.S. Da Silva, P. Wong-Wah-Chung, H.D. Burrows, M. Sarakha, Photochemica degradation of the plant growth regulator 2-(1-naphthyl) acetamide in aqueous solution upon UV irradiation, Photochem. Photobiol. 89 (2013) $560-570$

[37] C.C. Ryan, D.T. Tan, W.A. Arnold, Direct and indirect photolysis of sulfamethoxazole and trimethoprim in wastewater treatment plant effluent, Water Res, 45 (2011) 1280-1286.

[38] R. Alnaizy, A. Akgerman, Advanced oxidation of phenolic compounds, Adv. Environ. Res. 4 (2000) 233-244.

[39] C. Hu, Y.Z. Wang, H.X. Tang, Destruction of phenol aqueous solution by photocatalysis or direct photolysis, Chemosphere 41 (2000) 1205-1209.

[40] C.M. Glover, F.L. Rosario-Ortiz, Impact of halides on the photoproduction of reactive intermediates from organic matter, Environ. Sci. Technol. 47 (2013) 13949-13956.

[41] K.M. Parker, J.J. Pignatello, W.A. Mitch, Influence of ionic strength on triplet-state natural organic matter loss by energy transfer and electron transfer pathways, Environ. Sci. Technol. 47 (2013) 10987-10994.

[42] P.L. Miller, Y.P. Chin, Photoinduced degradation of carbaryl in a wetland surface water, J. Agr. Food Chem. 50 (2002) 6758-6765.

[43] Y. Maejima, H. Murano, T. Iwafune, T. Arao, K. Baba, Adsorption and mobility of aromatic arsenicals in Japanese agricultural soils, Soil. Sci. Plant Nutr. 57 (2011) 429-435

[44] A.A. Wang, S.X. Li, Y. Teng, W.X. Liu, L.H. Wu, H.B. Zhang, Y.J. Huang, Y.M. Luo, P. Christie, Adsorption and desorption characteristics of diphenylarsenicals in two contrasting soils, J. Environ. Sci. China 25 (2013) 1172-1179.

[45] P. Beck, Soil and ground-water remediation techniques, Geosci. Can. 23 (1996) 22-40.

[46] J.D. Rodgers, N.J. Bunce, Treatment methods for the remediation of nitroaromatic explosives, Water Res. 35 (2001) 2101-2111.

[47] F.I. Khan, T. Husain, R. Hejazi, An overview and analysis of site remediation technologies, J. Environ. Manage. 71 (2004) 95-122.

[48] L.Q. Ma, K.M. Komar, C. Tu, W.H. Zhang, Y. Cai, E.D. Kennelley, A fern that hyperaccumulates arsenic-a hardy versatile, fast-growing plant helps to remove arsenic from contaminated soils, Nature 409 (2001) 579.

[49] S.J. Hug, L. Canonica, M. Wegelin, D. Gechter, U. Von Gunten, Solar oxidation and removal of arsenic at circumneutral $\mathrm{pH}$ in iron containing waters, Environ. Sci. Technol. 35 (2001) 2114-2121

[50] H. Genc, J.C. Tjell, D. McConchie, O. Schuiling, Adsorption of arsenate from water using neutralized red mud, J. Colloid Interface Sci. 264 (2003) 327-334.

[51] X.H. Guan, H.R. Dong, J. Ma, L. Jiang, Removal of arsenic from water: effects of competing anions on $\mathrm{As}(\mathrm{III})$ removal in $\mathrm{KMnO}_{4}-\mathrm{Fe}(\mathrm{II})$ process, Water Res. 43 (2009) 3891-3899. 